\title{
Sobre a Preparação e a Composição em Terapia de Grupo: Descrições Construcionistas Sociais
}

\author{
Concerning Preparation and Composition in Group Therapy: \\ Social Constructionist Descriptions \\ Emerson F. Rasera ${ }^{a} \&$ Marisa Japur ${ }^{b^{*}}$ \\ ${ }^{a}$ Universidade Federal de Uberlândia, ${ }^{b}$ Universidade de São Paulo-RP
}

\begin{abstract}
Resumo
A definição construcionista do grupo terapêutico como uma prática discursiva enfatiza o caráter de negociação do processo de preparação e composição do grupo. Considerando esta perspectiva, o objetivo deste trabalho é compreender como determinadas formas de conversar contribuem para o processo de preparação e composição de um grupo de apoio para portadores do HIV. O grupo estudado consistiu de 10 sessões com 4 participantes. As sessões foram gravadas e transcritas. Através da análise discursiva dos momentos grupais, foi possível descrever a preparação para o grupo através de três processos conversacionais de: co-responsabilização do participante e construção inicial do pedido; co-responsabilização do terapeuta e renegociação do contrato; e 'aproximação discursiva' das descrições dos participantes. Em relação à composição do grupo, a inclusão no grupo não foi ditada a priori a partir de características do indivíduo, mas implicou um exercício de 'engajamento relacional' entre terapeuta e participantes.
\end{abstract}

Palavras-chave: Construcionismo social; terapia de grupo; composição do grupo.

\begin{abstract}
The constructionist definition of group therapy as a discursive practice emphasizes the character of negotiation in the process of group preparation and composition. Considering this perspective, the objective of this study is to comprehend how certain ways of talking contribute to the process of preparing and composing a support group for people living with HIV. The group that was studied had 10 sessions with 4 participants. The sessions were tape recorded and transcribed. By using discursive analysis on the transcripts of the group sessions, it was possible to describe the preparation for the group as involving three conversational processes: initial construction of demand and the participant's co-responsibility; renegotiation of the contract and the therapist's co-responsibility; and the 'discursive approach' of participant's descriptions. In relation to group composition, the inclusion of the participant in the group a priori was not based on the individual's characteristics but it implied an exercise of 'relational engagement' between therapist and participants.

Keywords: Social constructionism; group therapy; group composition.
\end{abstract}

\section{Terapia de Grupo e Construcionismo Social}

O construcionismo social consiste em um conjunto variado de diferentes contribuições teóricas produzidas na Psicologia nos últimos anos (Gergen, 1997; Shotter, 1993; Spink, 1999). De forma geral, tais contribuições enfatizam a especificidade cultural e histórica das formas de conhecermos o mundo e reconhecem a primazia dos relacionamentos na produção e sustentação do conhecimento. Podem ser divididas em dois subgrupos, quais sejam, "light constructionism" e "dark constructionism” (Danzinger, 1997). O primeiro se refere a aqueles autores para os quais a vida pode ser transformada através de uma abertura à multiplicidade do discurso, e assim, privilegiam o nível microssocial no estudo da construção do conhecimento. O segundo associa os autores que enfatizam os aspectos não-discursivos dos

Apoio: FAPESP/CNPq. Parte da Tese de Doutorado (PPG Psicologia -FFCLRP/USP) de Rasera, sob orientação de Japur.

* Endereço: FFCLRP USP, Av. Bandeirantes, 3900, 14090 910,

Ribeirão Preto, SP. mjapur@ffclrp.usp.br relacionamentos humanos, buscando analisar como o corpo e as estruturas sociais se constituem como locais de produção de poder, e privilegiam as estruturas macrossociais no estudo da produção do conhecimento.

As contribuições do construcionismo, especialmente do "light constructionism", se espalharam para o campo da Psicoterapia (Gergen \&Warhuus, 2001; Grandesso, 2000; McNamee \& Gergen, 1998), no qual têm influenciado algumas propostas terapêuticas tais como a terapia narrativa de White e Epston (1990), os processos reflexivos de Andersen (1999) ou a abordagem colaborativa de Anderson (1997), entre outras.

Estas propostas enfatizam, de diferentes formas: a análise do processo social de construção dos sentidos; uma postura de co-construção entre terapeuta e cliente, redimensionado a postura de especialista (Andersen, 1999; Anderson, 1997); o olhar sobre os relacionamentos nos quais o cliente está envolvido e nos quais constrói determinados sentidos; uma atenção aos valores e aos resultados pragmáticos dos 
discursos que são construídos no contexto terapêutico (White \& Epston, 1990); a multiplicidade de formas de descrever um problema (Andersen, 1999); e um discurso de potencialidades positivas e de construção de realidades futuras (White \& Epston, 1990).

Tais propostas não devem ser consideradas como “... técnicas ou formas instrumentais de conversar, mas como uma postura filosófica através da qual buscamos ao mesmo tempo estar informados pelas idéias construcionistas, e mantermo-nos abertos às condições momentâneas da conversação e ao significado de certas negociações" (Rasera, 2004, p.56).

No campo da terapia de grupo também encontramos algumas contribuições construcionistas (Becvar, Canfield, \& Becvar, 1997; Green \& Stiers, 2002; Guanaes, 2004; O'Leary, 2001; Rasera \& Japur, 2001, 2003) em propostas de utilização de equipes reflexivas em grupo (Chen \& Noosbond, 1999), de terapia grupal narrativa com pessoas com depressão (Laube \& Trefz, 1994) ou abusadas sexualmente na infância (Adams-Westcott \& Isenbart, 1996), bem como o uso de cartas em grupos psicoterápicos (Chen, Noosbond \& Bruce, 1998).

No Brasil, em uma tentativa de trazer o convite construcionista ao campo da terapia de grupo, Rasera (2004) propôs uma redescrição da terapia de grupo, definindo o grupo como uma prática discursiva, ou seja, uma forma de criar realidades relacionais através da linguagem. Esta redescrição teórica está associada a outras redescrições práticas, tais como: o contrato grupal como o meio de delimitar algumas condições de produção de sentido; a composição grupal como um processo de negociação entre terapeuta e participantes; o problema e a mudança como construídos na linguagem; o terapeuta como um parceiro conversacional; e a duração do grupo sendo definida a partir do entendimento do grupo como uma intervenção éticopolítica.

\section{A questão da preparação dos participantes e a composição do grupo}

Tradicionalmente, a sessão de preparação é descrita como uma forma de promover uma participação mais produtiva dos participantes, diminuindo expectativas irrealistas e conseqüentemente, o nível de atrito e ansiedade grupal, e a taxa de abandono dos participantes. Segundo Salvendy (1996), esta preparação pode ser realizada de diferentes formas, desde a aplicação de questionários sobre o participante, a apresentação de vídeos ou a distribuição de folhetos sobre psicoterapia de grupo, bem como sessões nos quais o terapeuta esclarece sobre o contrato grupal.

Em uma revisão das pesquisas sobre preparação para a terapia de grupo Kaul e Bednar (1994) apontam a eficácia de diferentes formas de preparação para o grupo. Contudo, se por um lado, parece haver um consenso quanto à necessidade de realizar algum tipo de procedimento de preparação para o grupo, por outro lado, resta compreender como ele contribui para os resultados obtidos. De forma geral, os estudos avaliados, baseados em um modelo experimental, apresentam uma ênfase na análise de resultados, desprivilegiando uma análise dos processos microssociais que sustentam a relação entre o terapeuta e os participantes.

A perspectiva construcionista, ao focalizar os modos como as pessoas constróem e dão sentido ao mundo em que vivem, pode contribuir em termos teóricos e práticos para este entendimento. Segundo Rasera (2004), a partir da redescrição do grupo como uma prática discursiva, a distinção entre o processo de composição e preparação do grupo é redimensionada. Pautado pela idéia que o processo grupal é um processo de negociação, este se inicia na preparação e composição do grupo. A partir de uma indicação inicial do terapeuta, a entrada de um participante no grupo deve ser discutida com cada participante. Neste momento, busca-se que cada participante se coloque de forma compromissada com o outro, numa posição que possa facilitar tais negociações no grupo. As ações de preparação consistem assim numa forma de criar uma arena conversacional na qual seja possível o diálogo.

Esta forma de pensar a composição grupal não é orientada por critérios sócio-demográficos ou diagnósticos privilegiados pelo terapeuta, mas enfatiza a atenção aos sentidos dados por cada participante às características dos outros.. Trata-se de um processo de negociação que evita uma definição a priori dos processos de inclusão/exclusão, bem como da homo/heterogeneidade grupal. Esta passa a ser entendida como um processo de construção das descrições de si dos participantes, que se inicia num diálogo com o terapeuta e se desenvolve através da interação ativa entre os mesmos.

\section{Objetivo}

O objetivo deste trabalho é compreender como determinadas formas de conversar contribuem para o processo de preparação e composição de um grupo de apoio fechado, de curta duração, para pessoas portadoras do HIV em uma ONG/Aids de Ribeirão Preto, a partir das propostas do construcionismo social.

\section{Método}

\section{O Grupo Estudado}

O grupo de apoio de curto prazo para pessoas portadoras do HIV aqui estudado teve como objetivo promover conversas dialógicas que permitissem a construção de outras formas de viver com HIV. O terapeuta buscou construir uma parceria conversacional marcada pela reflexão, negociação e co-responsabilização com os outros participantes. Além de 2 ou 3 sessões individuais de seleção e preparação para o grupo, o grupo teve 10 sessões grupais semanais de 1 h30 de duração, uma conversa final e uma conversa de seguimento após três meses do término do grupo, com cada participante. Ele foi composto por 4 participantes e o terapeuta: Pedro, 45 anos, sabia de sua soropositividade há 9 meses, buscou o grupo para ter com quem conversar, 'colocar suas coisas pra fora' e se sentir melhor; Marina, 53 anos, profissional liberal de nível superior, sabia-se portadora há 5 meses, e 
necessitava conversar sobre a revelação de sua soropositividade para sua família; Tiago, 30 anos, sabia-se portador há 9 anos, e buscava um jeito mais feliz de viver com HIV; Ricardo, 31 anos, sabia-se portador há 4 meses, e precisava saber mais sobre a doença, como enfrentar o preconceito e contar para sua família sobre a soropositividade; e o terapeuta, 29 anos, psicólogopesquisador, há 6 anos atendia pessoas portadoras do HIV, é o primeiro autor deste artigo.

\section{As Sessões de Preparação}

As primeiras conversas com cada participante potencial do grupo consistiram em sessões de acolhimento, de uma hora de duração, na qual o terapeuta buscou identificar o motivo pela procura do atendimento, entender a forma de enfrentamento existente até então, e discutir as possibilidades de cuidado com o participante. Estas conversas serviam também como uma oportunidade do participante conhecer o terapeuta, a instituição, sua estrutura, objetivos e regras, para então decidirem conjuntamente o encaminhamento a ser tomado. A partir das decisões de encaminhamento decorrentes destas conversas é que se foi compondo o grupo. Estas conversas iniciais tinham duas funções simultâneas: criar um contexto de diálogo e preparar para o grupo. O participante trazia os sentidos sobre sua vida e sua busca de mudanças julgados relevantes de serem apresentados ao terapeuta e ele buscava refletir com cada um as implicações sobre estas descrições da vida, da mudança e do grupo. Este processo visava promover descrições do participante sobre o atendimento escolhido e seu projeto de mudança. Através destas conversas se iniciava a construção do grupo como uma realidade negociada entre cada participante e o terapeuta. Esta construção foi pautada por sentidos relativos ao que o grupo poderia ser e produzir.

\section{A Constituição e Análise do Corpus}

Os dois passos metodológicos utilizados na constituição do corpus correspondem à gravação em fita cassete de todos os momentos do grupo, bem como o registro em um diário de campo a respeito da vivência do primeiro autor deste trabalho neste processo. A análise do corpus consistiu em: 1) Transcrição e edição de todas as conversas do grupo estudado; 2) Leitura flutuante, curiosa e intensiva da transcrição; 3) Seleção de momentos das sessões de preparação: considerando o objetivo de compreender como determinadas formas de conversar contribuem para o processo de preparação e composição de um grupo, escolhemos analisar trechos da transcrição de uma sessão de preparação, cuja riqueza facilita a visualização de diversos aspectos relativos à compreensão do grupo como uma prática discursiva - a sessão de preparação de Pedro. Além disso, trechos da sessão de preparação de Marina serão analisados, visando explorar aspectos específicos discutidos a partir da análise da sessão com Pedro; e, 4) Análise dos momentos selecionados. O processo de análise dos momentos selecionados buscou apontar o contex to que se construía a partir dessas conversas e as negociações aí necessárias, tentando respeitar a seqüência das conversas e a troca de turnos entre os participantes. Baseados em uma teoria relacional do significado (Gergen, 1997) buscamos rastrear o processo de suplementação dos enunciados e as ontologias relacionais que se construíam nas relações entre os participantes.

\section{Pedro e Marina: Preparando-se para/o Grupo}

A escolha das sessões de Pedro e Marina se deve ao caráter peculiar das mesmas e as diferentes tarefas de preparação demandadas. Pedro era um participante que exigia uma preparação cuidadosa para o grupo: tratava-se de uma pessoa com vários comportamentos auto-destrutivos, muito deprimido, que não sabia ao certo como sua participação em um grupo poderia ajudá-lo, nem estava, inicialmente, muito disposto a falar no grupo. Era necessário assim promover seu envolvimento com a terapia e a vida. Marina, por sua vez, dado o conjunto de participantes no momento de início do grupo, seria a única mulher do grupo, situação esta contraindicada pela literatura. Sua preparação implicava lidar com o risco do isolamento no grupo dada a diferença de gênero existente. A análise dessas duas sessões dará visibilidade ao processo pelo qual se deu a negociação que tornou possível que Pedro e Marina se tornassem membros do grupo.

\section{Acolhendo e Posicionando Pedro para a Terapia}

A sessão de preparação de Pedro escolhida para essa análise é a sua terceira sessão individual, a última antes do início das sessões grupais. Esta sessão de preparação em específico pode ser entendida como uma conversa de negociação explícita, ou seja, ambas as partes oferecem suas descrições da situação e então passam a investigar, uma junto a outra, as possibilidades de barganha, para uma conseqüente redefinição da situação, suas possibilidades e limites. O primeiro momento da sessão consiste no acolhimento e investigação de situações recentes ocorridas com Pedro. Ele conta como tem tido menos dor de cabeça, como tem conversado mais com os profissionais de saúde e falado menos sobre aids com sua esposa.

Terapeuta: Entendi. Da primeira semana, você falou assim, "Ah, que eu saí daqui, fiquei pensando, depois entrou a outra semana, já pensou outra coisa. ”... O que que você ficou pensando? Você lembra?

Pedro: Ah, pensando besteira de novo...

Terapeuta: Voltou a pensar besteira? Que tipo de besteira que você voltou a pensar, Pedro?

Pedro: Ah, mesma besteira que sempre dá. (Tosse) Que, que eu falo, né? Que eu pego meu, meu (???) de noite, os outro pede pra sarar e eu peço pra Deus me levar eu embora, só isso aí.

Terapeuta: Entendi. É, e a Milene [esposa de Pedro] tá sabendo que você continua pedindo isso?

Pedro: Não. Num falei mais nada pra ela, não. Eu peço sozinho, quieto, num canto. ... (ele conta como a mulher continua 'sem paciência') 
Terapeuta: É... o Pedro, mas apesar disso, hoje eu tô achando você mais sorridente, você sabia?

Pedro: É?

Terapeuta: Da outra vez que você veio aqui estava mais... Pedro: Mais derrubado?

Terapeuta: É, mais derrubado. Aconteceu alguma coisa pra você ficar menos derrubado?

Pedro: Não, isso aí, eu sei lá, né?

Terapeuta: Por que que você acha que você tá menos derrubado?

Pedro: Sei lá eu, é por Deus.

$\cdots$

Terapeuta: Né? É... que que você está, esperando do grupo? Pedro: Eu, eu peço pra Deus, ou saro duma vez ou morre duma vez, num fica aí infernizando os outros, né? Fica dando, fazendo trapaiada, os outros sofrendo por causa da gente, ou sara ou... ou morre. Que venha falar pra mim, falar que ele quer fazer, o que ele fazer tá bom.

Terapeuta: É? Então, é, e você, o que que você tem feito pra ajudar Deus tomar essa decisão?

Pedro: Ah, eu tenho feito, eu, não, eu só peço pra ele, né? Terapeuta: Você só tá rezando?

Pedro: Só, eu só peço pra ele, só.

Terapeuta: E num tem mais nada que você faz além de rezar pra ajudar a Deus?

Pedro: Não, eu, o que que eu vou fazer mais?

Terapeuta: Que que você acha que você poderia? Vamos pensar sobre isso?

Pedro: (silêncio curto) Vamos...

Terapeuta: Que tipo de coisa você acha que você pode ajudar Deus? Primeiro, você tem interesse em ajudar Deus a tomar essa decisão, se te leva ou se te cura?

Pedro: Claro que eu tenho, né? Que se num tiver, eu também num tiver, também, também num... Precisando, se a gente num vê, num fazer um pedido, também, num querer ajudar, também, também, como diz a moda do outro, "Ele também lava a mão", né?

Terapeuta: Ele lava as mãos? Então, tem, as coisas também dependem de você?

Pedro: Depende.

Terapeuta: É, e nessas coisas que dependem de você, que que você, é, qual que é a coisa mínima que você acha que você está disposto a fazer pra ajudar Deus? (SP de Pedro, pp.1-2)

Nesta conversa, podemos ver como Pedro mudou sua relação com o que era seu problema. No começo da conversa ele reclamava e pedia a Deus para morrer. Ele estava em uma posição passiva, esperando pelo desejo divino. Seu próprio desejo de viver estava ameaçado. É como se toda a sua vida estivesse saturada pelo problema com nenhuma possibilidade de transformação. Esta posição de Pedro está claramente baseada em uma narrativa dominante (White \& Epston, 1990) sobre o viver com HIV/aids na qual a pessoa com aids morrerá rapidamente, podendo ser salva apenas por um milagre, por Deus.

Neste momento, algumas posturas terapêuticas logo tentariam mostrar-lhe a importância de viver. Contudo, considerando uma postura construcionista (Anderson, 1997), o terapeuta não buscou trabalhar visando certos resultados específicos neste momento, mas focalizar o processo, o relacionamento com Pedro e suas decisões. Não foram investigados os detalhes de sua história que justificasse tal decisão. Não se trata de não valorizar a vida e a importância de um projeto de vida. Ao contrário, este é um dos compromissos ideológicos que perpassam as atividades da ONG na qual este grupo de apoio foi realizado, mas sim, da forma como se conversar sobre isso. Neste momento, o terapeuta buscou estar aberto a outros aspectos que percebia além do conteúdo de morte trazido por Pedro, como sua postura na sessão, sorridente e aparentemente menos depressiva, diferente da sessão anterior. Tentando focalizar desta diferença, o terapeuta pergunta sobre ela. Era um convite a considerar outros aspectos de sua vida que talvez ele não estivesse reconhecendo. Naquele instante, ele não percebia que parecia melhor.

Neste momento de acolhimento de Pedro, o exercício de perguntar se torna fundamental. Trata-se de uma postura de curiosidade, que busca abertura, que se interessa por outras histórias, e respeitando seu vocabulário favorece a construção de outras descrições sobre as questões trazidas por ele.

Conversando com Pedro sobre sua postura na sessão naquele momento, o terapeuta busca construir a oportunidade para que ele fale como era capaz de enfrentar aquelas dificuldades, promovendo um senso de ação e potência em Pedro. Novamente, ele se refere ao "desejo de Deus". O terapeuta pergunta então sobre o desejo de Deus e novamente, tentando colocá-lo em uma perspectiva diferente, uma posição mais ativa em sua relação com Deus, pergunta a ele o que ele poderia fazer para ajudar Deus.

Esta questão pode parecer paradoxal se pensada em relação à crença religiosa na qual Deus decide sobre a vida humana - como Pedro descrevia. Desta forma, Deus e Pedro estavam completamente separados. Mas também era possível ver que Pedro, desde sua primeira fala sobre esta questão percebia duas possibilidades para a decisão divina, e também, que de alguma forma ele poderia influenciar este processo através de suas rezas. Fazendo esta questão, o terapeuta busca ampliar a conversa sobre estas diferenças, atentando para não introduzir 'diferenças muito incomuns' (Andersen, 1999). A análise desta questão também é um exemplo do dialogismo na conversa, na qual tanto Pedro como o terapeuta contribuíram para seu desenvolvimento: as perguntas do terapeuta incluíram as palavras de Pedro e convidaram a um novo movimento em direção a outra possibilidade de significação.

Inicialmente, ele ficou um pouco confuso, dizendo que poderia apenas rezar. A questão do terapeuta era um convite a ver o mundo de uma maneira diferente. O terapeuta tenta então ir um passo adiante, abrindo a possibilidade de Pedro pensar em fazer algo mais. Neste momento, trata-se de colocálo em uma posição mais ativa em relação a seu próprio cuidado e a vida. E então, ele se descreve como alguém que queria seriamente ajudar Deus e de que ele era um agente importante na decisão divina. 
Esta forma de descrever a relação com Deus e sua relação com sua vida mudou: de uma posição na qual ele não sabia o que fazer para um entendimento comprometido de como as coisas dependiam também de sua decisão. Ele não apenas esperava pela decisão divina sobre sua vida/morte, mas começava a pensar sobre sua responsabilidade por ela. E então, Pedro e o terapeuta começam a conversar, no momento seguinte, sobre como ele poderia ajudar a Deus, iniciando pelas coisas mais simples de serem feitas. Este cuidado em escolher o que fazer também se relaciona à construção de ações que possam ser uma evidência de seu potencial e um convite a outras ações. É uma forma de fortalecer seu senso de ação pessoal.

Conversar sobre Deus e morte pode trazer vários desafios, mas à medida que se enfatiza os sentidos dados pelo cliente, se aceita seu entendimento, e se conversa com ele em seus próprios termos, novas possibilidade de vida podem ser conjuntamente construídas. Esta conversa sobre o que ele poderia fazer para auxiliar Deus em sua decisão foi a primeira de outras que ocorreram nas sessões do grupo sobre as suas próprias ações e seu senso de controle sobre sua própria vida - uma questão muito significativa para muitas pessoas que vivem com HIV/aids.

Através destas conversas, constrói-se uma posição de coresponsabilização de Pedro por sua vida, desenhando assim um certo pedido para o trabalho terapêutico. É a partir da construção do pedido de Pedro e de sua posição de querer se cuidar que se torna possível o tipo de conversa proposta em um grupo de apoio.

Esta conversa sobre mudanças ocorridas a partir das duas sessões iniciais combate uma visão estereotipada das sessões de preparação como algo que existe apenas para preparar para algo que virá. Não se trata de pensar a conversa sobre o contrato grupal como uma forma de garantir como as coisas serão. As sessões de preparação são elas próprias um contexto de negociação e construção de si e do grupo. Neste sentido, as sessões de preparação não são diferentes de qualquer outra sessão do processo grupal. A especificidade destas sessões se refere a um tema da conversa intencionalmente trazido pelo terapeuta como uma forma de promover determinadas relações entre os participantes consigo próprios e com os outros, inclusive o terapeuta.

\section{Negociando a participação de Pedro no grupo}

Dando continuidade à sessão, após certo posicionamento de Pedro, o terapeuta investiga com Pedro quais suas expectativas sobre o que vem a ser o grupo. A partir de suas falas, busca compreender quais as antecipações de Pedro relativas ao papel dos participantes e as formas de relação entre eles. Em seguida, o terapeuta apresenta as regras do contrato grupal e investiga as impressões de Pedro a respeito do mesmo.

O objetivo desta conversa é criar uma oportunidade na qual o participante possa conversar com o terapeuta, em um contex to de escuta atenta, de foco nos sentidos trazidos pelo participante, sobre suas possíveis reações sobre o proposto como forma de funcionamento do grupo, bem como a respeito dos outros participantes e as formas de lidar com eles. Tratase do exercício de refletir sobre a ação frente a um determinado contexto, podendo contar com as contribuições do terapeuta não apenas sobre os conteúdos que o levam à terapia, mas inclusive sobre o próprio grupo proposto pelo terapeuta como o contexto apropriado de ajuda para o participante. É o jogo de abertura e negociação dos sentidos sobre o contrato promovido pelo entendimento do grupo como uma prática discursiva.

Apesar desta preparação ser uma conversa na qual não havia um roteiro de instruções sobre o grupo, ela possuía uma intenção geral que fez com que a conversa tivesse uma certa lógica de funcionamento. Ela se pautava pela construção de um entendimento comum sobre o que poderia vir a ser o grupo, a identificação de dificuldades imaginadas no cumprimento do contrato e a exploração de possíveis formas de solução destas dificuldades. Esta conversa se colocava como uma abertura para redimensionar determinados organizadores práticos do grupo.

Neste momento da sessão, a negociação explícita relativa ao contrato do grupo acontece. Em relação a Pedro, a principal questão se refere às condições de expressão de suas opiniões. O contrato proposto especificava que todos os participantes deviam compartilhar seus pensamentos no grupo. Em seu exercício de adaptar as regras às suas possibilidades, Pedro, a partir das perguntas do terapeuta, vai aos poucos tornando problemática essa regra a qual tem então, neste momento, que ser negociada na conversa. Frente às características das restrições apresentadas por Pedro, foram construídas outras possibilidades de lidar com esta regra.

Terapeuta: É, você acha que vai ser fácil você dar a sua opinião e falar das coisas, ou você acha que não, como que você acha isso, ô Pedro?

Pedro: Bom, quando eu achar que eu devo falar, e eu falo, quando eu ver que num, que num, num tem nada que falar eu abaixo minha cabeça, eu fico quieto e deixo os outros falar.

Terapeuta: É, que situação você acha que não vai dar pra você falar, que você vai ter que abaixar a cabeça?

Pedro: Hum, depende do meu, se eu converso isso na hora, se tá, se eu estou de acordo, se eu num estou, pra aí que eu vou falar. Depois que eles falar eu falo. Até que eles estão conversando, minha cabeça está pensando no que eles estão falando.

Terapeuta: Hum? E, mas depois você vai poder falar, ou você num vai poder falar?

Pedro: Ah, aí depende o, conforme que for eu posso falar ou num posso falar, né?

Terapeuta: O que que faria você não falar? Você imagina numa situação, assim, que você acha melhor não falar nada? (SP de Pedro, p.17)

Pedro continua a especificar as condições nas quais não expressará sua opinião claramente, mantendo-se calado frente à conversa dos outros participantes. Se esta era uma condição que Pedro colocava em suas contribuições, era necessário explorar como se poderia possibilitar uma forma de participação na qual pudesse expressar suas opiniões 
verbalmente, facilitando a conversa entre os participantes. Se por um lado, processos de reflexão e diálogos internos são parte fundamental do grupo, a interação verbal constitui uma forma de comunicação entre as pessoas fundamental ao processo de negociação.

Terapeuta: É, deixa eu te perguntar uma outra coisa: você acha que você seria capaz, assim, que você, ficaria numa boa, sem ter dor de cabeça, nem nada, se você falasse para o grupo porque que você acha que a conversa num é boa? Pedro: Não, mais é, sei lá, né? O que, que eu posso falar, sempre, vou ter que escutar, ficar escutando primeiro depois eu vou ver, né, sempre vou escutar primeiro, prestar atenção primeiro, pra depois...

Terapeuta: O Pedro, nessas situações, é, talvez, tenha dois jeitos que a gente pode agir, né. Se numa conversa que a gente acha que num, a gente pode tanto, falar, porque que a gente acha que essa conversa não tem que tomar esse caminho e falar.

Terapeuta: Entendi, mas então, é, e daí, assim, uma coisa que pode fazer também, Pedro, é propor um outro assunto, porque senão, se você acha que um tá falando palhaçada, o outro fala palhaçada, o outro fala palhaçada, você vai sair daqui falando "Ah credo, aquele povo lá só fala palhaçada" (SP de Pedro, pp. 17/18).

Contudo, estas alternativas não constituem recursos adequados para Pedro.

Pedro: Às vezes, lá em casa mesmo, eu chego em casa e falo assim, a pessoa me conta uma coisa lá, eu chego em casa falo "Oh, é, assim, assim, assim". Chega aquela pessoa perto de mim, fala pra mim "não, é mentira sua, você, num é assim não". A pessoa, "é assim, assim, assim.” Eu num, eu num sou esse que já vai discutindo, bri, fica bravo porque uma pessoa falou pra mim. Então eu falo, falo pra minha mulher, "Você viu um burro falando? é melhor passar de, como mentiroso do que eu, caçar confusão. Então deixa eu como mentiroso aqui. Passou, num passou? Se é pra arrumar confusão fica pior".

Terapeuta: Eu entendi. Eu entendi. É durante o grupo a gente vai tentar prestar atenção nessas coisas, tá bom? ... Daí, eu vou fazer o que? Eu vou falar pro grupo “ Oh gente, hoje, que que tá acontecendo? Hoje parece que só um que está falando, o resto está tudo quieto. Que que será? Está todo mundo discordando ou está todo mundo concordando e pensando? (SP de Pedro, p.19).

A regra de partilhar os pensamentos no grupo não é possível de ser seguida sempre a partir de seu modo de ver as coisas. Não se trata de algo que possa ser simplesmente aceito, pois é algo que em sua vida cotidiana não é utilizada. Para ele, a expressão de sua opinião é algo que pode gerar confusão, sendo a discordância na conversa percebida como potencialmente perigosa, o que o faz evitar se pronunciar em determinados momentos. Esta negociação explicita o caráter peculiar das conversas em grupos terapêuticos, nos quais se busca uma nova organização da conversa, diferente daquela proposta em outros contextos. No grupo se propõe um tipo de conversa que é diferente. Aqui a discordância e o conflito são vistos como momentos que podem ser úteis nos processos de mudança, levando a novos posicionamentos dos participantes. Contudo, aceitando sua condição peculiar de se colocar no grupo, e os limites desta regra, o terapeuta se propõe a zelar pelo tipo de conversa que se propõe como adequada pelo contrato.

A organização desta conversa aponta que à medida que Pedro colocava posições que não traduziam diretamente a regra de expressar suas opiniões, isto demandava outras questões, até que fosse possível formular uma alternativa na qual a regra fosse respeitada bem como seu senso de bem-estar preservado.

Curiosamente, nesta preparação de Pedro, de negociação do contrato, construiu-se uma nova postura, não de Pedro, mas do terapeuta. Não se trata de avaliar uma postura como certa ou errada a partir de um olhar externo sobre o contrato grupal, mas uma negociação que considerando as diferenças entre os participantes, a partir das suas possibilidades, possa promover as condições para a construção de novos sentidos através das conversas no grupo. É esta abertura para a ressignificação do contrato que traz para primeiro plano o aspecto construído do grupo nesta sessão de preparação. Como podemos ver, a conversa sobre o contrato grupal exigiu negociações que envolviam tanto as posturas de Pedro quanto as minhas. Esta sessão não constitui assim, apenas um momento de preparação de Pedro, mas do próprio terapeuta. É a dimensão relacional do processo de preparação que exige uma atenção para todos os envolvidos na conversa. Trata-se de um momento de construção não só do grupo, mas de um relacionamento, de uma conexão entre as inúmeras de uma rede de identidades recíprocas formada neste contexto, a do terapeuta com a de Pedro.

Em relação a Pedro, mais do que o foco no respeito às suas restrições sobre a participação no grupo, da não consideração destas restrições como um critério de exclusão da participação de Pedro, esta forma de compreender a sessão de preparação enfatiza o aspecto produtivo deste tipo de conversa, ou seja, da possibilidade de Pedro se colocar de forma ativa na negociação das relações nas quais participa. É uma conversa específica de sua relação com o terapeuta, mas que cria a oportunidade dele se posicionar de forma ativa na construção de projetos de vida. A relação de Pedro com o contrato não é de algo que lhe é externo, sobre o qual lhe cabe apenas aceitar. Nesta negociação, cria-se a oportunidade para que Pedro coloque em questão sua possibilidade de seguir o contrato, redimensionando-o.

\section{Conversando com Pedro sobre os outros Participantes}

Após esta negociação sobre o contrato, outro momento na conversa de preparação se refere à apresentação dos outros participantes do grupo. A partir de dados como idade, sexo, tempo que se sabe portador, e motivo de buscar o grupo, o terapeuta apresenta a Pedro a sua descrição dos outros três participantes do grupo. 
Esta apresentação tem por objetivo convidar Pedro a conversar sobre as relações imaginadas com estas pessoas. Por um lado, a apresentação de Pedro se baseia em recortes que enfatizam uma conversa sobre descrições soropositivas dos participantes, produzindo, neste contex to de um grupo de apoio para pessoas portadoras, recortes já antecipados mas que confirmam um certo modo de olhar e se descrever os participantes. Por outro lado, estas negociações sobre o contrato e os participantes têm como base uma postura do terapeuta orientada para o futuro. Este convite permite explorar as dificuldades antecipadas, impressões iniciais, bem como aumentar o conjunto de descrições de si em relação aos outros participantes do grupo, num processo de responsabilização e familiarização com o diferente.

Esta postura se pauta pelo abandono de uma visão de um self essencial e verdadeiro que se revela nas interações, a qual contra-indicaria este tipo de procedimento que 'contaminaria' as descrições de self dos participantes com os recortes utilizados pelo terapeuta para sua apresentação, circunscrevendo outras possibilidades de sentido.

Inicialmente, Pedro não se manifesta sobre as pessoas, mas os problemas por elas vividos. É como se ele não aceitasse o convite a pensar uma relação com estas pessoas. Sua primeira reação frente a esta apresentação é a de relatar suas respostas pessoais aos dilemas comuns enfrentados por outros participantes, especificamente à revelação da condição de soropositividade para familiares e amigos. Mais do que isso, ao descrever suas posturas Pedro mostra o caráter adequado e necessário das mesmas, questionando aqueles que não fizeram o mesmo que ele. É curioso observar que Pedro que não expressa suas opiniões, suas discordâncias, ou oposições, também pode se apresentar como Pedro que expressa suas opiniões de forma direta e imediata. Trata-se de um exemplo da construção situacional de si, a partir de uma mudança no tópico da conversa na sessão.

Terapeuta: Que que você achou dessas coisas que você ouviu?

Pedro: Essas, é o que eu te falei "Oh, cada um acha, que, pensa, eu, eu, sei lá, eu já assumi, já contei pra todo mundo, que, num adianta eu esconder uma coisa que é realidade ... Num dianta... (troca de fita) Falei, que eu tenho um problema desse. Eu, eu escondo de você. Amanhã, depois, você vê eu subindo na cadeira, o sujeito que nunca viu eu de costas, ele fala assim, "Desgraçado do Pedro. Ele tinha os po, ele tinha os problema dele, que amigo que eu sou dele, que ele num teve confiança de chegar em mim e falar pra mim?"

Terapeuta: É, Pedro, você acha que você consegue por essa tua opinião no grupo?

Pedro: Tá certo.

Terapeuta: Tá?

Pedro: Eu consigo... (Pedro conta como contou para um amigo sobre sua soropositividade e foi acolhido) Agora, vamos, vamos supor, eu moro, vamos supor, eu moro com a minha mulher... eu chegava lá no médico, falava assim pra mim, e eu chegava em casa, eu escondia dela. Eu tava certo? Não, num tava. Eu acho que não, na minha cabeça eu num tava certo...
Terapeuta: Ô Pedro, você consegue imaginar porque que essas pessoas, têm dois que num contaram né, que querem conversar sobre isso, porque que esses dois, é, porque que eles ainda não contaram? Você consegue entender isso?

Pedro: Ah, eu sei lá. É a cisma, a cisma da pessoa ver que a pessoa num, num compreende ele, né, deve ser isso (SP de Pedro, pp.23-24).

A primeira resposta de Pedro à apresentação dos outros participantes não é curiosa, nem reflexiva, nem explicitamente de ajuda. Ele busca imediatamente justificar porque tomou uma atitude diferente daqueles. Neste momento, o terapeuta não o questiona a partir das diferenças das situações, mas busca entender os conteúdos do que ele falava a partir de uma posição particular. O terapeuta tenta conversar sobre como ele poderia colocar isso na conversa com os outros participantes investigando como seria possível conversar sobre esta diferença. Pedro insiste em seu ponto de vista. A partir disto, o terapeuta o convida a se colocar no lugar do outro e imaginar os motivos para que não tivessem feito o mesmo. Trata-se de um exercício que busca colocar o participante de forma aberta a poder conversar e conhecer o outro. É o caráter preparatório da sessão. Tal como o bemestar consigo próprio, uma preocupação com o bem-estar dos outros participantes deve ser buscada. Se através destas sessões, destas conversas iniciais, se constrói a possibilidade dele estar aberto aos sentidos trazidos pelo terapeuta, é preciso também criar espaços discursivos para a construção de sua relação com os outros participantes.

Após este momento, o terapeuta continua a questionar Pedro sobre como imagina participar de um grupo com estas pessoas. Ele acredita que será fácil pois estão “... tudo eles no mesmo barco, com, com o mesmo problema. Eu vou achar estranho o que? Esconder uma coisa deles pra quê? Se nós está tudo no mesmo, na mesma canoa?" (SP de Pedro, p.24) Através desta fala afirma-se a homogeneidade grupal para Pedro - o que poucos minutos antes era diferente, agora se torna parecido.

Parece haver tensões e ambigüidades no discurso de Pedro a respeito dos outros participantes, ora visto como iguais, ora como diferentes, bem como em sua forma de participar, ora não sendo capaz de dizer o que pensa, em outras, que poderia dizer tudo. Tais ambigüidades apontam para o caráter múltiplo e situacional das descrições de Pedro sobre si mesmo e o grupo. É nas brechas e ambigüidades existentes nestas descrições, ou melhor, na possibilidade permanente de ressignificação que se desenvolvem as conversas do grupo.

Nesta sessão de preparação, ao mesmo tempo em que se buscava investigar as dificuldades, e negociar alternativas, também se buscava promover as potencialidades de cada participante a partir de sua história pessoal.

Pedro: ... Eu cheguei, ontem, ontem-ontem, na casa dum amigo meu, que ele tava, bem, bem pior que eu, desempregado, eu falei, falei, "Eu, eu num posso te ajudar mas, amanhã vou sair cedo, vou, vou arrumar quem possa te ajudar". E fui no, no cara que tomava conta de mim... 
Fui num, no outro, fui na M., no $\mathrm{O}$, um monte, falei "Oh, fulano lá, que tava com nós, tá assim, assim, assim. Você que pode ajudar ele, eu num posso". "Não Pedro, nós vai ajudar”. E tentei, e tentou resolver o problema dele, ele ficou contente.

Terapeuta: Então, entende como, você fez a sua parte, que era ir avisar os outros... Então, eu acho que isso, num grupo, é, isso é muito importante Pedro, que é o que? No fundo, no fundo, Pedro, todo mundo tem como ajudar. É que as pessoas num podem ajudar do mesmo jeito, né. Cada um pode ajudar de um jeito. (SP de Pedro, p.27)

Frente ao relato de Pedro, de como ajudou um amigo que estava em dificuldades, o terapeuta ressalta a capacidade de Pedro ajudar, e considerando a particularidade da contribuição de cada participante em um grupo, aponta como tal capacidade de Pedro pode ser útil no contexto grupal que irá participar. Trata-se de uma autodescrição de Pedro que através desta conversa é incluída no processo de construção de Pedro como participante do grupo. Esta busca de investigar dificuldades imaginadas e promover potencialidades de ação está relacionada à tentativa de promover um posicionamento ativo de Pedro em relação ao grupo, um discurso sobre seu envolvimento com o mesmo, de sua possibilidade de participação, e sua capacidade de construir novos projetos em sua vida.

\section{Conversando com Marina sobre os outros Participantes do Grupo}

Se através da análise de trechos da sessão de preparação de Pedro é possível discutir a sessão de preparação como uma prática discursiva situada, a análise da composição grupal pode ser enriquecida se considerarmos alguns trechos da sessão de preparação de Marina. Marina é a única mulher do grupo. Tradicionalmente, isto seria contra-indicado pela literatura sobre composição dos grupos (Salvendy, 1996). Esperar-se-ia, no mínimo, a participação de mais uma outra mulher no grupo. Contudo, assumindo a homogeneidade como algo construído (Rasera, \& Japur, 2003), quais os sentidos dados pelos participantes, especialmente por Marina, sobre a composição do grupo?

O trecho a seguir é parte da sessão de preparação de Marina. Tal como na sessão realizada com Pedro, após negociarem o contrato, o terapeuta apresenta as descrições dos outros participantes do grupo e investiga as impressões de Marina sobre o mesmo.

Terapeuta: É isto, né, o grupo...

Marina: São essas pessoas...

Terapeuta: ...são essas 4 pessoas e eu, por enquanto, é isso...

Marina: Só essas?

Terapeuta: ... que a gente vai ter. Você imaginava um monte de coisa e agora...

Marina: É...

Terapeuta: ... o concreto das coisas, são, é isso né. É claro que é...

Marina: Só tem eu de mulher?
Terapeuta: Só tem você de mulher.

Marina: (riso)

Terapeuta: Que...

Marina: E pelo que dá pra perceber é a mais velha de todos... (rindo)

Terapeuta: Hum... E o que que você acha disso tudo?

Marina: Bom... Vai ser bom... Com certeza. Eu acho que a gente num vem pra ajudar, eu acho que, a gente precisa de ajuda, né, e se eu falo que eu vinha ajudar, aí já seria, assim, muita pretensão minha, né, pretensiosa. Eu acho que, é trabalhando, um falando, um ajudando, um empurra de cá, uma cotovelada e quem sabe a gente fica um pouco mais forte, não tão vulnerável, né. (SP de Marina, p.23)

A reação inicial de Marina, tal como Pedro, não tem a ver com os outros participantes em si, mas consigo própria. Ela busca confirmar seu entendimento como sendo a única mulher e ressaltando que ela era a mais velha. Quando a questiono de maneira aberta sobre a composição grupal, ela faz comentários sobre a possibilidade de ajuda deste grupo, enfatizando a possibilidade de apoio e ajuda que pode existir no grupo. No trecho a seguir, esta possibilidade de apoio faz outras diferenças entre os participantes terem um caráter secundário.

Terapeuta: ... Quais você acha que vão ser? Eu queria saber como que você imaginaria, tanto quais vão ser as tuas facilidades nesse grupo, é, como, bem como as dificuldades que você encontraria.

Marina: Ah, eu num penso assim. Eu num devo pensar assim.

Marina: Se eu tiver aí dentro e ouvir falar, "Ah, você é Pedro, eu sou Tiago". Não vai funcionar, né? Então eu acho que a, a gente tem que ter, além de querer ajudar, a dignidade de respeitar, seja ele quem for. É um grupo de 5 pessoas, com dificuldades e sofrimento e fim de papo... Pra mim, aqui num tem idéia, num tem, sexo, num tem nada. É, são pessoas precisando, de uma forma ou de outra, tornar mais fácil, como lidar com essa doença. Eu acho que isso que é mais importante.

Terapeuta: É, eu achei engraçado na hora, no que eu acabei de falar da composição, você falou assim, "Ai, eu sou a única mulher...

Marina: (riso)

Terapeuta: ... e mais velha... (riso)

Marina: Mais velha, ainda... (rindo) Não, eu já sei que eu sou a mais velha, mais tudo bem...

Terapeuta: É...

Marina: Não, num tem nada. Mais isso também, é pra eu, só nós aí, que tá tudo... E são, é sexo masculino. Num quer dizer nada. É aquilo que eu falo pra você, "A partir do momento que você é soropositivo..." Ai, foi isso que o doutor P. falava: "Num escolhe cor, sexo, profissão". E a partir do momento que ela existe, são mil reações diferente, ela é dolorosa, ela machuca. E, e ela que fez isso, num importa. Não, eu só notei que no grupo é só eu. Mais num tem nada a ver, e, é aquilo que eu falo, "Aqui eu num vou ser uma mulher. Eu vou ser uma pessoa com o mesmo problema dele, né? A mesma dificuldade, tudo, né?" (SP de Marina, p.24) 
Quando questionada sobre as possíveis dificuldades a serem enfrentadas, ela se recusa a pensar o grupo nestes termos. Novamente, ressalta a importância de cuidar do sofrimento vivido pelas pessoas, buscando fazer de qualquer outra característica pessoal algo insignificante.

As diferenças de gêneros podem ter valores diferentes para pessoas diferentes em contexto específicos.

Através destas falas, enfatiza-se a vivência da soropositividade, borrando outras diferenças entre os participantes. Trata-se de uma conversa que promove a construção ativa da homogeneidade grupal.

Estes movimentos na produção dos sentidos sobre a composição do grupo nos fazem repensar os chamados critérios de tal composição. Parece que os participantes se esforçam discursivamente para construir o grupo como um contexto adequado para a expressão e participação de cada um deles.

\section{Um Jeito de Compor o Grupo}

As conversas iniciais, ou sessões de preparação deste grupo de apoio, como uma prática discursiva situada, possibilitam a criação de uma realidade relacional entre terapeuta e participantes através de três processos: a) coresponsabilização do participante e construção inicial do pedido; b) co-responsabilização do terapeuta e negociação do contrato; e c) aproximação discursiva das descrições dos participantes, ou a construção da homogeneidade.

O processo de co-responsabilização do participante consiste no primeiro passo de construção do mesmo como participante de um grupo de apoio. É necessário, conjuntamente, operar recortes situacionais sobre as possibilidades de conversar no grupo. A partir da curiosidade do terapeuta, circunscrita pelos objetivos do grupo, e das histórias selecionadas pelo participante é construído um pedido do mesmo sobre o que conversar no grupo, de forma tal que ambos se responsabilizem pelos sentidos aí produzidos. Esta coresponsabilização do participante implica o terapeuta em um processo semelhante, levando-o inclusive a uma redescrição dos termos do contrato e sua forma de participação. Este processo de redescrição de si e do grupo a partir dos processos anteriores está associado num grupo de apoio para pessoas portadoras do HIV a um processo de aproximação discursiva das descrições dos participantes, promovendo o acolhimento dos participantes através da ênfase na vivência comum da soropositividade.

Ao mesmo tempo em que se propõe uma abertura para a negociação da composição grupal, parece haver um certo limite para a mesma. Os trechos das sessões de preparação de Marina e Pedro iluminam este processo. Apesar do espaço para discutir sobre a composição, Pedro e Marina não o fazem no sentido de discutir a participação de um participante potencial. Podem fazer críticas a determinadas posturas de alguns participantes, mas parecem partir do pressuposto que esse é o grupo.

Talvez porque tendo o terapeuta indicado estes participantes, deve haver uma lógica para ser assim e manifestar qualquer oposição a is to é questionar o saber do terapeuta. As inúmeras situações em que Marina utiliza a expressão "né" parecem ser tentativas de buscar a concordância e apoio do terapeuta, buscando sempre monitorar a aceitação de seus modos de entender sobre o que conversavam. Os questionamentos em voz alta de Pedro, sobre o que ele iria falar frente aos convites de negociação, podem também ter este mesmo sentido. A quase ausência de comentários sobre o contrato quando da primeira sessão do grupo, pode ter um sentido muito semelhante. Além disso, talvez por perceberem os outros como precisando de ajuda, questionar a participação de qualquer um deles seria posicionar-se como uma pessoa cruel. Em ambas as situações, questionando o terapeuta, ou colocando-se de forma crítica e severa em relação ao outro, o participante pode ter ameaçado o seu próprio lugar no grupo.

Parece, assim, que o convite a conversar sobre o grupo, refletir sobre possíveis dificuldades e formas de enfrentar, é produtivo à medida que gera um tipo de relação entre terapeuta e participante, e deste consigo próprio. Através desta conversa, entende-se que o próprio grupo pode ser objeto da conversa. Apesar de uma descrição trazida pelo terapeuta sobre o grupo e o contrato, ela não é completamente fechada, sendo possível sua negociação. Há uma tensão criativa que faz com que terapeuta e participantes sejam postos como responsáveis pela relação construída.

Por outro lado, tal convite enfrenta um limite em suas possibilidades de abertura e negociação, marcado pelos sentidos sobre a divisão institucional dos papéis sociais, reafirmada pelos participantes durante a sessão de preparação, pela qual, em última instância, cabe ao terapeuta a responsabilidade de definir quem participa do grupo e aos participantes serem acolhedores e apoiadores.

Frente a tal tensão, a resposta dos participantes à apresentação dos outros participantes é no sentido de, como disse Pedro, considerar que "todos estão no mesmo barco", buscando apagar inclusive outras diferenças que fazem parte de suas vidas, como a diferença de sexo e idade. Na fala mais enfática de Marina: "Aqui eu num vou ser uma mulher. Eu vou ser uma pessoa com o mesmo problema dele, né, a mesma dificuldade, tudo, né?”. Trata-se da produção ativa da homogeneidade a partir das negociações do próprio contrato e composição grupal.

Através desta análise podemos ver que a inserção de um participante implica uma série de negociações que explicitam o caráter construído do grupo e seus participantes. Nas quatro negociações aqui analisadas - sobre a participação de Pedro, sobre o contrato grupal, sobre a relação dele com os outros participantes, na sessão de preparação de Pedro; e sobre o contrato na sessão de preparação de Marina podemos ver um jogo no qual o terapeuta busca definir as formas de participação e relacionamento no grupo, e o participante se esforça por redefinir tais descrições do terapeuta. Este processo implica o terapeuta e os participantes em outras redefinições e acordos.

A negociação das regras do grupo, das formas específicas de se descrever como participando do mesmo, consiste num exercício de 'engajamento relacional' (McNamee, in press) 
no qual conjuntamente se aposta na possibilidade de estar juntos num grupo. Assim, as condições de inclusão no grupo não estão ditadas a priori a partir de características do indivíduo (homem/mulher, heterossexual/homossexual, usuário de droga/não usuário), nem das regras estabelecidas unilateralmente pelo terapeuta (o contrato grupal), mas implica um plano de mútua responsabilidade assumido de forma pessoal entre terapeuta e cada participante, no qual se constroem descrições partilhadas sobre a participação no grupo, as quais podem ser objeto da conversa novamente ao longo das sessões. O foco destas conversas iniciais não está no já dado, mas no processo de construção da realidade grupal promovido pelas conversas entre terapeuta e participantes.

As formas de se descrever do participante na sessão de preparação, bem como seus projetos, não determinam de forma completa e linear, as conversas futuras no grupo, nem seu modo específico de participar. Isto estará necessariamente circunscrito pelas condições imediatas do contex to conversacional. Contudo, a partir de uma definição da identidade pessoal como uma descrição existente numa rede de identidades recíprocas, as descrições de um participante, bem como se tornam recursos contextuais na construção de determinadas justificativas em outras conversas nas quais participam. É a dimensão relacional desta conversa que se expande potencialmente como contexto de outras conversas. Assim, as descrições negociadas nesta sessão podem ser novamente utilizadas nas conversas de outras sessões, circunscrevendo-as e talvez exigindo novas negociações, que as fazem novamente abertas a outros sentidos.

Contudo, se as descrições de si e dos outros não devem ser consideradas como critério da composição do grupo, o que o deveria ser então? Tipo de pedido, questão, queixa ou demanda? Compromisso com a tarefa? Mas tudo isto também não é algo que se constrói? Porque buscar a homogeneidade de algum tipo se a entendemos como construída nas relações presentificadas entre os participantes? O foco que se propõe aqui não é considerar as experiências anteriores dos participantes como fatos dados, determinantes lineares da tomada de decisão de um terapeuta distanciado, mas chamar a atenção para o modo como através das conversas o terapeuta e os participantes vão construindo realidades relacionais, seja sustentando descrições anteriores, fortalecendo-as, seja destacando algumas nuances, pequenas diferenças que convidam a novas descrições, e sentidos sobre pessoas e histórias já narradas.

A partir destas análises, abandona-se uma preocupação do terapeuta sobre a composição do grupo como uma forma a priori de garantir um melhor desenvolvimento grupal. Convida-se, então, a uma atenção permanente do terapeuta ao processo conversacional em todos os seus momentos de construção do grupo. Nestas conversas iniciais sobre conversas grupais futuras, o grupo começa a existir enquanto realidade relacional entre terapeuta e participantes, tanto como uma prática - uma forma específica de conversar, como uma identidade - uma forma específica de se descrever como participante do grupo.

\section{Referências}

Adams-Westcott, J. \& Isenbart, D. (1996). Creating preferred relationships: the politics of recovery from child sexual abuse. Journal of Systemic Therapies, 15, 13-30.

Andersen, T. (1999). Processos reflexivos. Rio de Janeiro: Instituto Noos/ITF.

Anderson, A. (1997). Conversation, language and possibilities. New York: BasicBooks.

Becvar, R.J., Canfield, B.S., \& Becvar, D. (1997). Group work. London: Love.

Burr, V. (1995). An introduction to social constructionism. Londres: Routledge.

Chen, M. \& Noosbond, J.P. (1999). Un-sticking the stuck group system: process illumination and the reflecting team. Journal of Systemic Therapies, 18(3), 23-36.

Chen, M., Noosbond, J.P. \& Bruce, M.A. (1998). Therapeutic document in group counseling: an active change agent. Journal of Counseling and Development, 76, 404-411.

Danziger, K. (1997). The varieties of social construction. Theory and Psychology, 7, 399-416.

Gergen, K.J. (1997). Realities and relationships. Cambridge: Harvard University Press.

Gergen, K.J. (1999). An invitation to social construction. Londres: Sage.

Gergen, K.J. \& Warhuus, L. (2001). Terapia como construção social: características, reflexões, evoluções. In M.M. Gonçalves \& O.F. Gonçalves (Eds.), Psicoterapia, discurso e narrativa: a construção conversacional da mudança (pp.27-64). Coimbra: Quarteto.

Grandesso, M. (2000). Sobre a reconstrução do significado. São Paulo: Casa do Psicólogo.

Green, Z. \& Stiers, M.J. (2002). Multiculturalism and group therapy in the United States: a social constructionist perspective. Group, 26(3), 233-246.

Guanaes, C. (2004). A terapia de grupo como recurso conversacional: o processo de negociação de sentidos em um grupo ambulatorial de curta duração em saúde mental. Tese de doutorado não-publicada, Faculdade de Filosofia, Ciências e Letras de Ribeirão Preto da Universidade de São Paulo. Ribeirão Preto, SP.

Kaul, T.J,. \& Bednar, R.L. (1994). Pretraining and structure: parallel lines yet to meet. In A. Fuhriman \& G.M. Burlingame (Eds.), Handbook of group psychotherapy (pp. 155-188). New York: John Wiley.

Laube, J. \& Treftz, S. (1994). Group therapy using a narrative theory framework: application to treatment of depression. Journal of Systemic Therapies, 13(1), 29-37.

McNamee, S. (in press). Therapy as social construction - back to basics and forward toward challenging issues. In T. Strong \& D. Pare (Eds), Furthering talk: Advances in the discursive therapies. New York: Kluwer Academic/Plenum Press.

McNamee, S. \& Gergen, K.J. (Eds.) (1998). A terapia como construção social. Porto Alegre: ArtMed.

Nightingale, D.J. \& Cromby, J. (Eds.) (1999). Social constructionist psychology. Buckingham: Open University Press.

O'Leary, J.V. (2001). The postmodern turn in group psychotherapy. International Journal of Group Psychotherapy, 51, 473-487.

Rasera, E.F. (2004). O grupo como construção social: aproximações entre o construcionismo social e a terapia de grupo. Tese de Doutorado não-publicada, Faculdade de Filosofia, Ciências e Letras de Ribeirão Preto da Universidade de São Paulo. Ribeirão Preto, SP. 
Rasera, E.F. \& Japur, M. (2006). Sobre a Preparação e a Composição em Terapia de Grupo: Desconstruções Construcionistas Sociais.

Rasera, E.F. \& Japur, M. (2003). Grupo de apoio aberto para pessoas portadoras do HIV: a construção da homogeneidade. Estudos de Psicologia, 8, 55-62.

Rasera, E.F. \& Japur, M. (2001). Contribuições do pensamento construcionista para o estudo da prática grupal. Psicologia: Reflexão \& Crítica, 14, 201-209.

Salvendy, J.T. (1996). Seleção e preparação dos pacientes e organização do grupo. In H.I. Kaplan \& B.J. Sadock (Eds.), Compêndio de psicoterapia de grupo (pp.63-72). Porto Alegre: ArtMed.

Shotter, J. (1993). Conversational realities. Londres: Sage.

Spink, M.J. (Ed.) (1999). Práticas discursivas e produção de sentido no cotidiano. São Paulo: Cortez.

White, M. \& Epston, D. (1990). Medios narrativos para fines terapéuticos. Buenos Aires: Paidós. 